126

76 巻 761 号 $(2010-1)$

\title{
四脚ロボット「Rush」を用いたバウンド歩容生成*
}

益 田 俊 樹*1, 木 村 浩*2
末 廣 尚 士*3, 高 瀬 國 克*1

\section{Emergence of a Bound Gait Using Quadruped Robot "Rush"}

\author{
Toshiki MASUDA*4, Hiroshi KIMURA, \\ Takashi SUEHIRO and Kunikatu TAKASE \\ ${ }^{* 4}$ Graduate School of Information Systems, University of Electro-Communications, \\ 1-5-1 Chofugaoka, Chofu-shi, Tokyo, 182-8585 Japan
}

\begin{abstract}
We have been studying on quadruped gait using our quadruped robot "Rush", which has rotational passive joints. Among quadruped gait, "bound gait" is simple and easy to emerge for quadruped robot. Thus, most of researches on quadruped robot running have dealt with bound gait. But, bound gait of most quadruped robot differed from four legged mammals. This paper shows that the bound gait similar to four legged manmals can realized by controlling the position of the center of gravity of the robot body in both simulations and actual experiments.
\end{abstract}

Key Words: Mechatronics, Moving Robot, Legged Locomotion, Bouned Gait, Quadruped Robot, Emergence of Gait

1.は じめに

これまでに多くの四足動物の走行の研究が色々な面 から行われている，四足動物が行う走行歩容は，プロ ンク 1 , バウンド, 跳躍付きのトロット ${ }^{2}$, 跳躍付き のペース ${ }^{3}$, キャンター4, ギャロップ 5 などがある. この中でも四脚ロボットを用いた走行歩容の研究とし ては，バウンド歩容が単純で発生しやすいために多く の研究が行われている，バウンド歩容とは, 左右の前 脚と左右の後脚が跳躍期間を挟んで交互に地面に着地 する歩容である。しかし，バウンド歩容を安定させて 発生させる方法注制御面，機構面共に解明されていな い.ささら，多くの四脚ロボットが発生させているバ ウンド歩容と動物が行うバウンド歩容とは異なってい る。なぜこのように違いが生まれるのかはまだ不明で ある。

バウンド歩容の走行研究としては, Raibert $ら^{(1)}$ の 四脚ロボットの研究がよく知られている. Raibert ら の研究の優れている点は，走行制御を跳躍高さ，前進 速度，胴体姿勢の制御に分離し，それぞれの運動がリ ミットサイクルを構成するような簡単な制御則を与え た点，脚式走行の機構としてバネ-質量系を用いた点 である、そして、動物が行うバウンド歩容やトロット

\footnotetext{
* 原稿受付 2009 年 6 月 22 日。

*1 正員, 電気通信大学情報システム学研究科( $182-8585$ 調 布市調布方

*2 正員, 京都工芸繊維大学工芸科学研究科 ( $\mathbf{W} 606-8585$ 京都 市左京区松ヶ崎橋上町)

*3 電氛通信大学情報システム学研究科.

E-mail : toshiki@taka.is.uec.ac.jp
}

歩容を実現させている，しかし，なぜこれらの歩容が 簡単な制御系や機構で発生し安定化できるのかは明 らかにしなかった. Full ら ら $^{(2)}$ ，走行の安定性の研究 で，筋肉や腱の持つバネ特性を利用して構成される受 動ダイナミクス (バネ-質量系) が運動のリズムを生成 することに注目した。その結果，CPG(Central Pattern Generator) のようなリズムジェネレータや位相調節の ようなセンサフィードバックの必要なしで運動が生成 されると主張している。このバネ-質量系に抒ける自己 安定性に関する研究で，Seyfarth ら ${ }^{(3)}$ は，SLIP(Spring Loaded Inverted Pendulum) と呼ばれる一脚モデルを用 いて受動走行の安定な固定点を Matlab 用いて挆索 した，そして，胴体速度や跳躍高さなどをセンサで計 測することなく，遊脚着地角度をある一定值に保つだ けで運動が安定化されることを示した。このことを自 已安定化 (Self Stabilization) と呼ぶ，自己安定化の考え は四脚走行ロボットの研究に大きな影響を与え Talebi ら ${ }^{(4)}$ は,「ScoutII」のような四脚走行ロボットを開発し， バウンド歩容を実現させている.さらに，Zhang ら は，探索された固定点に収束させるために遅延フィ一 ドバック制御を用いて静止から定常状態になるまでの バウンド歩容の遷移を実現させている。しかし，詳細 は後に述心゙るが，この二つの研究で発生したバウンド

\footnotetext{
四本の足が同時に着地し同時に離脱する歩容.

2対角の足が跳躍を挟んで交互に着地する歩容.

${ }^{3}$ 左側と右側の足が跳躍を挟んで交互に着地する步容。

4後述するギヤロップの速度が遅くなった歩容.

51 本の足が着地 $\rightarrow$ 跳躍を繰り返す步容.
} 


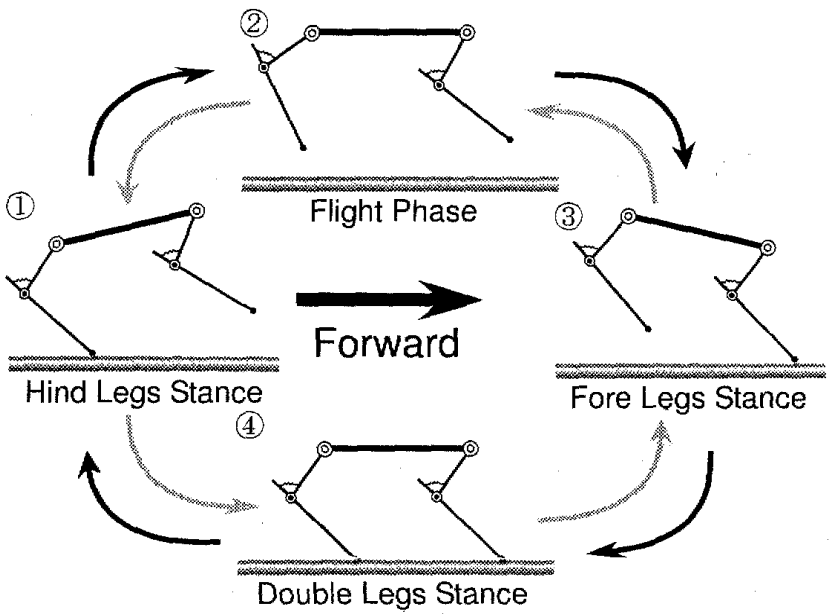

Fig. 1 Bound gait by quadruped robots

歩容は動物が行うバウンド歩容とは異なっていた。

そこで本研究では，より生物に近いモデルの四脚口 ボット「Rush」を用いてこの動物が行うバウンド歩容 を発生させると共に，なぜ動物が行うバウンド歩容が 発生するか定シミュレーションや実機で検証した。

\section{2. バゥンド歩容}

2.1 四脚ロボットにおけるバウンド歩容 バウン ド歩容とは左右前脚, 左右後脚が跳躍期間を挟んで交互 に着地する歩容である、後脚が接地した後の跳躍期間の ことを"Extended Flight Phase"(6) と呼び，また，前脚が 接地した後の跳躍期間のことを“Gathered Flight Phase” と呼ぶ.これまでの四脚ロボットの研究により Z hang らは, 図 1 に示すような時計回りで Extended Flight Phase のみのバウンド歩容を発生させ, Poulakakisら ${ }^{(7)}$ は, Extended Flight Phase のみや図 1 の反時計回り の Gathered Flight Phase のみのバウンド歩容を分けて シミュレーションにより検証している，そして，我々 の過去の研究 ${ }^{(9)}$ では, 簡単な制御法によって不安定な バウンド歩容から実機の脚長を変化させることによっ て Gathered Flight Phase タイプのみ発生させること ができた。しかしながら，これらのバウンド歩容は図 1 中の 4 に示すような両脚支持期 (Double Legs Stance) ${ }^{6}$ が存在し，云わば四脚ロボット限定で発生するバウン ド歩容であり，四足動物ではこのようなバウンド歩容 を発生させていない。

2.2 四足動物におけるバウンド歩容四足動物 が行らバウンド歩容とは，図 2 に示すような

1. 後脚接地

6 前後左右すべての脚が同時に地面に着いている期間.

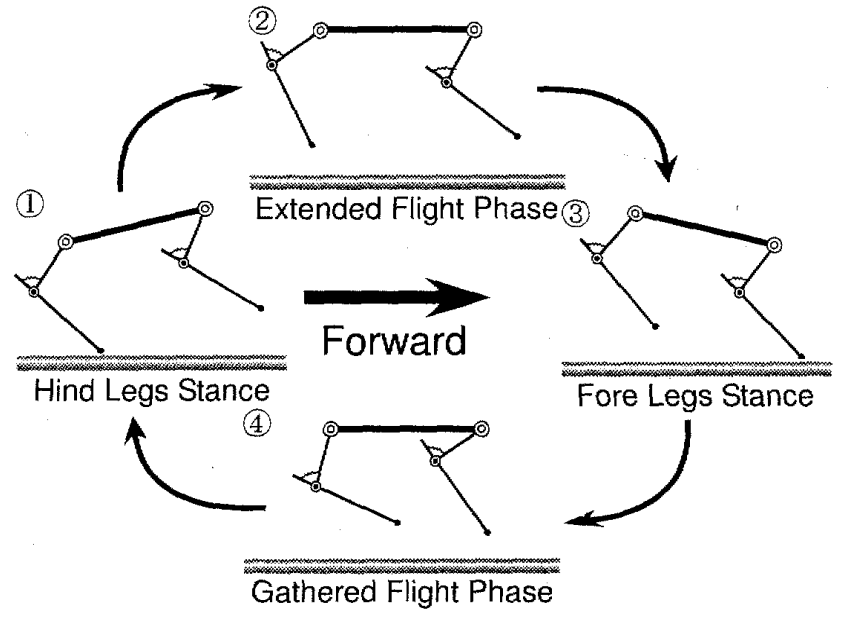

Fig. 2 Bound gait by legged mammals

2. 跳躍期間

3. 前脚接地

4. 跳躍期間

という順番でローテーションする歩容である.つまり， 歩容一周期につき二回の Flight Phase があるというこ とである．この一周期に二つの Flight Phase があるバ ウンド歩容をここでは, “Full Bound”と呼ぶことにす る.このように，従来の四脚ロボットが行うバウンド 歩容と動物が行うバウンド歩容は異なっていた。この Full Bound $の$ 研究としては, Poulakakis $ら^{(8)}$ は, シミュ レーション上で制御パラメータを変えて胴体の角速度 を上昇させることにより，発生させているが，実機で の実現は成されていない。

\section{3. 四脚走行モデルと四脚走行ロボット“Rush”}

3.1 四脚走行モデル 本研究では，バウンド歩 容の四脚走行を扱うために，図 3 に示すような知状 面内モデルを考える、このモデルは，剛体である胴体 と膝関節にバネが付けられた二リンク脚二本により構 成される．腰関節は能動関節で，滕関節は受動関節で ある.

3.2 四脚走行ロボット“Rush”図30走行モデ ルを元に図 4 に示すような四脚口ボットRush を開発 した。この Rushは，バネ-質量系として前後のそれぞ れの脚の腰関節と膝関節孛繫ぐ部分にバネが搭載され ている.そして，各脚の腰関節に一つずつモータが搭 載されており，腰関節が能動回転機構，膝関節が受動 回転機構しなっている．回転方向はいずれもピッチ方 向である. Raibert らや Talebi らの四脚ロボットとの 違いは，受動機構が直動ではなく回転機構を採用した 


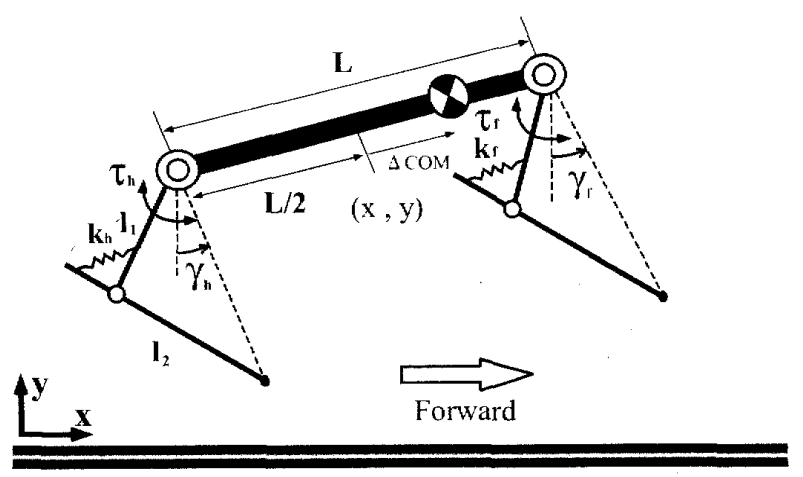

Fig. 3 Sagittal plane model

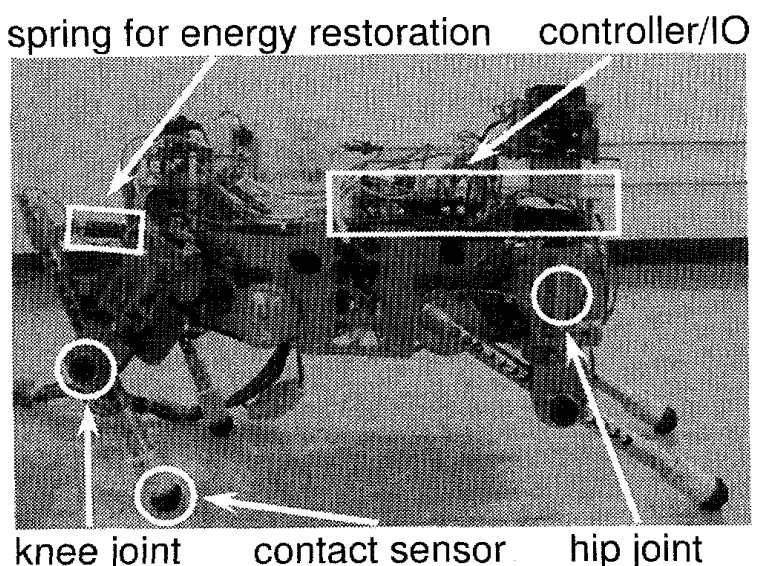

Fig. 4 Quadruped running robot: Rush. The size 38 $\mathrm{cm}$ in length and and $20 \mathrm{~cm}$ in width. The height of stand is $20 \mathrm{~cm}$.

ことである．実際の四足動物で脚機構が直動機構とい うのは存在しないので，Rushはより四足動物に近い 機構といえる．足先には，接地情報を取得するために 接地センサを搭載しており，コントローラ系はすべて 胴体上にあり，電源のみ外部から供給している。全体 の質量は $4.7 \mathrm{~kg}$ となっている. その他の物理パラメー 夕は表 1 に示す。

\section{Full Bound 歩容生成}

バネ-質量系の四脚ロボットにおける物理パラメータ とは, 胴体重量, 胴体重心, 脚長, バネ定数などが考え られる，我々の過去の研究で，前脚支持脚期間が非常 に短かったために，脚長を変化させることによって前 脚支持脚期間を長くした結果，不安定なバウンド歩容 から Gathered Flight Phase のみのバウンド歩容を発生 させることができたが, Full Bound は発生しなかった. そこで今回は，脚長よりバウンド歩容に影響を与えや すいと考えられる胴体重心位置を胴体の中心 $(L / 2)$ か ら変化させると Full Boundが発生するのではないかと
Table 1 Physical parameter of the quadruped robot Rush

\begin{tabular}{l|l|l}
\hline \multicolumn{1}{c|}{ parameter } & \multicolumn{1}{c|}{ value } & \multicolumn{1}{c}{ units } \\
\hline \hline Total mass & 4.70 & $\mathrm{~kg}$ \\
\hline$L$ & 0.38 & $\mathrm{~m}$ \\
\hline Body width & 0.20 & $\mathrm{~m}$ \\
\hline$l_{1}$ & 0.14 & $\mathrm{~m}$ \\
\hline$l_{2}$ & 0.16 & $\mathrm{~m}$ \\
\hline Standing height & 0.2 & $\mathrm{~m}$ \\
\hline$k_{f}$ & 2.05 & $\mathrm{kN} / \mathrm{m}$ \\
\hline$k_{h}$ & 3.03 & $\mathrm{kN} / \mathrm{m}$ \\
\hline
\end{tabular}

考え，歩容にどのような影響を与えるのかを Rush を モデル化したシミュレーションにより検証を行い, 次 に実機で検証をする。

$4 \cdot 1$ 制御手法各脚の制御手法として, 遊脚相 と支持脚相を切り替えるための脚相 $\phi$ を以下の式のよ うに与える. 添字 $l=f, h$ であり，それでれ前脚 (fore) と後脚 (hind) を表す.

$$
\phi_{l}=\sin \left(\omega_{l} t+\varphi_{l}\right)+\phi_{0 l}, \omega_{l}=\frac{2 \pi}{T_{l}}
$$

$\omega_{l}$ は角速度， $\varphi_{l}$ は歩容を発生させるための初期位相, ここでは，バウンド歩容を生成させるために，前後で 位相差 $\pi$ を与えている， $\phi_{0 l}$ は，各脚の Duty 比を与え るオフセットであり， $T_{l}$ は周期である.

$\phi_{l}>0$ の場合，遊脚相とみなし，以下の式を用いる.

$$
\tau_{l}=K_{p}\left(\gamma_{l}-\gamma_{l}^{\prime o}\right)+K_{d} \dot{\gamma}_{l}
$$

$\gamma_{i}$ は支持脚目標離脱角度, $K_{p}, K_{d}$ は支持脚の $\mathrm{PD}$ ゲイ ンである。

$\phi_{l}<0$ の場合，支持脚相とみなし，以下の PD 制御 を用いて腰トルク $\tau_{l}$ を出力する.

$$
\tau_{l}=K_{p}\left(\gamma_{l}-\gamma_{l}^{\prime d}\right)+K_{d} \dot{\gamma}_{l}
$$

$\gamma_{i}^{d}$ は遊脚目標着地角度である。

\section{2. シミュレーションによる検証}

4.2.1 シミュレーションモデル 図 5 は図 3 に基 づいて作成した四脚シミュレーションモデルを示す. シミュレーションソフトには「Webots6」を用いる，足 先には実機同様，接地情報を測定するための接地セン サを搭載している.

4.2.2 シミュレーション結果＼cjkstart前節で説明したモ デルを利用し，胴体重心位置 $\triangle C O M$ を変化させるこ とによってバウンド歩容がどのように変化するかのシ ミュレーションを行った. 今回このシミュレーション 


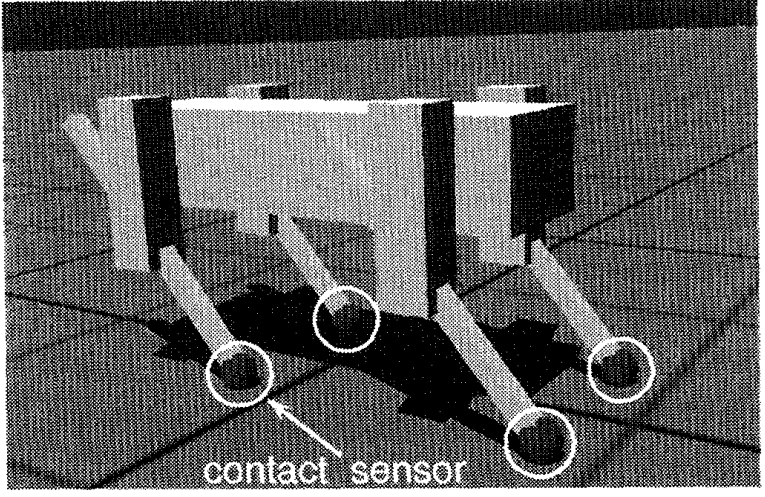

Fig. 5 Simulation model

Table 2 Values of the parameters used in simulations with running model

\begin{tabular}{l|l|l}
\hline \multicolumn{1}{r|}{ parameter } & fore leg & hind leg \\
\hline \hline$\varphi$ & 0 & $\pi$ \\
\hline$\phi_{0 l}$ & 0.16 & 0.09 \\
\hline$T(s)$ & 0.15 & 0.15 \\
\hline$\gamma^{\prime d}(\mathrm{rad})$ & 0.00 & -0.08 \\
\hline$\gamma^{\prime o}(\mathrm{rad})$ & -0.52 & -0.52 \\
\hline$\left(K_{p}, K_{d}\right)$ & $(30,2.00)$ & $(30,2.00)$ \\
\hline
\end{tabular}

では，30 秒間シミュレーションでモデルを走行させ， その9割が同一歩容であれば，その歩容が発生したと 判断することにした．表 2 にシミュレーションで用い た制御パラメータを示す。

図 6 は, $\Delta \mathrm{G}$ によりバウンド歩容が変化した前脚と 後脚の Duty 比の結果を示与. $\Delta \mathrm{G}$ は，図 3 により，胴 体の中心 $(L / 2)$ 加らの+方向の重心変位 $\triangle C O M$ と胴 体長さ $L$ で割った比

$$
\Delta G=\frac{\Delta C O M}{L}
$$

である. Duty 比は，

$$
\text { Duty ratio }=\frac{\text { Stance period }}{\text { Stance period }+ \text { Swing period }}
$$

で表される支持脚期間と遊脚期間で計算される比であ る. 実線が前脚, 点線が後脚の Duty 比を示す。

$\Delta G$ を増加させると，前脚の支持脚期間が長くなる. これにより, 前脚の Duty 比が増加していることがわ かる、 $\Delta \mathrm{G}$ が，0から0.05では, Extended Flight Phase のみや Gathered Flight Phase のみのバウンド歩容，ま た，前進するだけの不安定な歩容が発生していたが， 0.05 から 0.18 までは Full Bound が発生した。 $\Delta \mathrm{G}$ が 0.18 以上では，また不安定な歩容が発生した． $\Delta \mathrm{G}<0$ の時は後ろに倒れてしまったのでデータとしては載せ ていない.

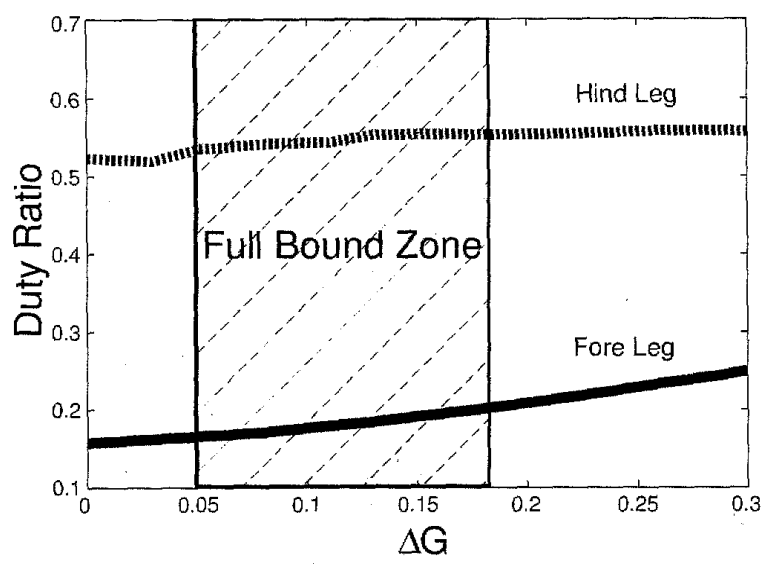

Fig. 6 Duty ratio result by simulation

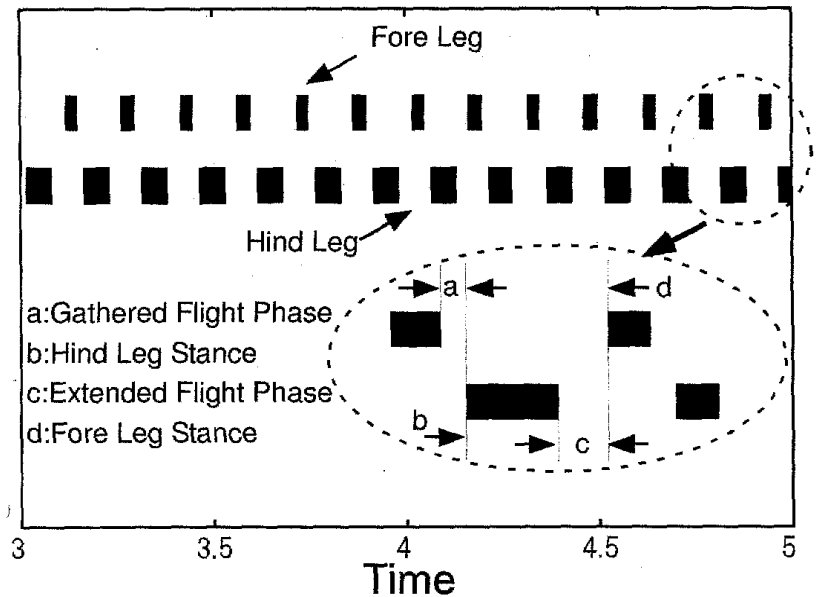

Fig. 7 Contact result by simulation

これにより現在の二リンク能動受動機構のシミュ レーションモデルにおいて，重心位置を適切な量だけ 前方に移動すると Full Bound 老発生させることがお かった。

図 7 は, $\Delta \mathrm{G}$ が 0.08 時 $(\triangle C O M=0.03 m)$ の前脚と後 脚によって接地センサから得られた結果である.図 7 中の a は Gathered Flight Phase，bは後脚が接地した時 間，cは Extended Flight Phase，dは前脚が接地した時 間を表している。この結果によると，前脚の支持脚期 間は短いが，Gathered Flight Phase と Extended Flight Phase の雨方が一周期に発生していることがわかる. この時の Duty 比は, 前脚 0.17 後脚が 0.54 であった。

$4 \cdot 3$ 実機による実験 シミュレーションの結果 を受けて次に実機による検証を行った。ここでは，図 4 に示した四脚ロボットRushを用いた実験の結果を示 寸.しかし，胴体重心位置 $\triangle C O M$ を変化させることは 実機では難しいので，制御系機器を胴体の前方に寄せ た時の $\Delta G$ が 0.08 であったため，この值を用いて走行 
Table 3 Values of the parameters used in experiments with Rush

\begin{tabular}{l|l|l}
\hline \multicolumn{1}{c|}{ parameter } & fore leg & hind leg \\
\hline \hline$\varphi$ & 0 & $\pi$ \\
\hline$\phi_{0 l}$ & 0.16 & 0.09 \\
\hline$T(s)$ & 0.15 & 0.15 \\
\hline$\gamma^{\text {td}}(\mathrm{rad})$ & 0.00 & -0.17 \\
\hline$\gamma^{\text {do }(\mathrm{rad})}$ & -0.52 & -0.61 \\
\hline$\left(K_{p}, K_{d}\right)$ & $(30,0.03)$ & $(30,0.03)$ \\
\hline
\end{tabular}

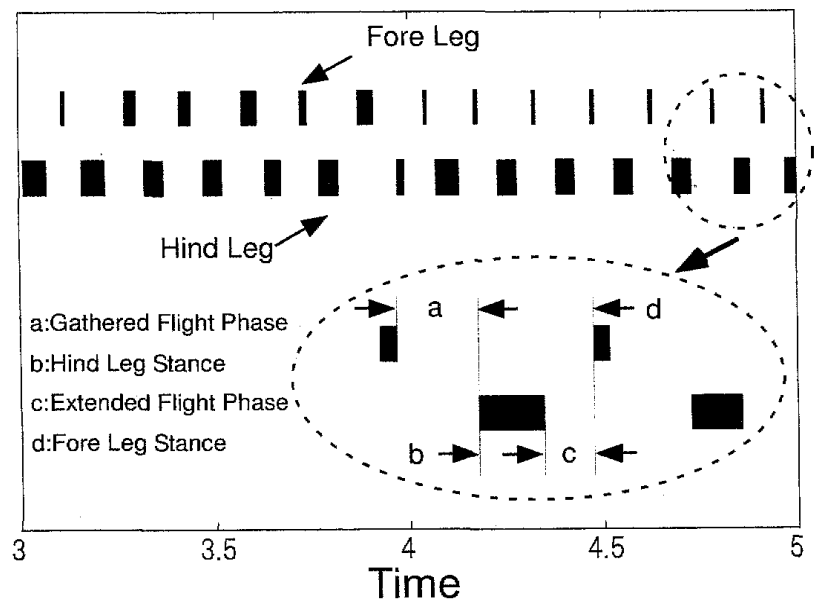

Fig. 8 experimental result by contact sensor

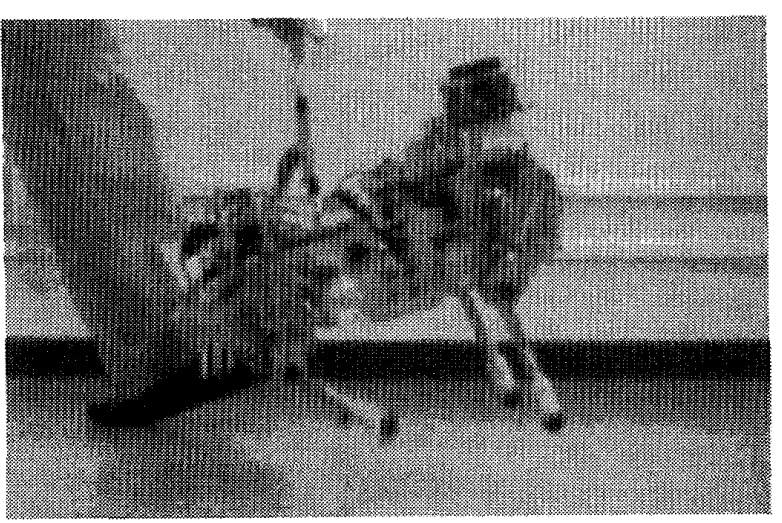

Fig. 9 Rush running by experiment

実験を行った. 表 3 に実験で用いた制御パラメータを 示寸．図 8 は，接地センサにより測定された結果であ る. シミュレーションの接地結果に比べて, Gathered Flight Phase が若干長くなっているが，Full Bound が 発生していることがわかる. Duty 比は前脚 0.17 後脚 0.42 であり,シミュレーションのDuty 比の結果に比 心，後脚の值が低くなっている，図 9 はFull Bound 発 生実験によるスナップ写真である.
4.4 考察，今回のシミュレーションと実機実験で は，後脚の目標着地角度 $\gamma^{t d}$ と目標離脱角度 $\gamma^{j o}$ の制御 パラメータが若干違うもののほとんど同じパラメータ でFull Bound が発生した。 しかし, 図 7 と図 8 を比較 すると，シミュレーションでは，Gathered Flight Phase より Extended Flight Phase のほうが長いが，実機では， Extended Flight Phase より Gathered Flight Phase うが長い。この理由は, シミュレーションの胴体モデ ルと実機の胴体の違いにあると考えられる. Gathered Flight Phase は，前脚と地面の衝突により発生するの で, 前脚のトルクや前脚の質量で Gathered Flight Phase の長さが決まる.シミュレーションでは, 胴体の密度 を一様に設定しているが，実機のほうではモータやギ アが胴体の端に搭載されているために実機では, 胴体 の中心より両端のほうが重くなっている．要するにシ ミュレーションの胴体のモデルをさらに精密にす扎ば このような違いは生じないと考えられる.

他の研究では, Extended Flight Phase と Gathered Flight Phase がどちらが長いかというと, Raibert ら ${ }^{(10)}$ のアニメーションとロボットによる研究では, Extended Flight Phase より Gathered Flight Phase のほうが長い という結果が得られている。これは我々の実機実験 の結果と一致している，そして，この知見は一般的 に四足動物において, 前脚が減速 (ブレーキ), 後脚 は加速 (トルク注入) の役割であることの説明を裏づ けしている。つまり, 前脚と地面の衝突から始まる Gathered Flight Phase は, 減速のために後脚に比べ, 地面との衝突力が強く跳躍期間が長くなる.さらに， Krasny $ら^{(6)}$ の研究を参考にすると, 後脚から跳躍期間 に人る Extended Flight Phase は加速の役割を担ってる ので Extended Flight Phase $の$ 間にトップスピードが発 生寸るという結果が得られている.

\section{5.お わりに}

この論文では，ニリンクの能動受動回転機構のバネー 質量系においてシミュレーションと実機により，動物 が行っているバウンド歩容と同じ Full Bound が発生さ せた．そして，本研究で用いたモデルにおいての Full Bound が発生する要因として，胴体重心を変化させる ことで Full Bound が発生することがシミュレーショ ンによりわかった。 さらに，シミュレーション結果を 用いて実機で一例ではあるが Full Bound を発生させ た。しかし，胴体重心の変化がどのように歩容に影響 を与えるのかのメカニズムについては，他のパラメー タの影響が大きく現象が複雑なので十分には解明でき なかった。 
今後は, Extended Flight Phaseのみや Gathered Flight Phase のみのバウンド歩容がどのように Full Bound と 関係しているかの条件を検証し，実機の Full Bound $の$ 評価や他の物理パラメータなどもシミュレーションで 検証する予定である.さうに，一般的な脚機構にお汁 る四脚モデルでも Full Bound の発生条件を見つけたい．

\section{謝、辞}

本研究の一部は科研費・特定領域研究「移動知」: 領 域番号 454 の研究助成を受けて行われました。

\section{文献}

(1) Raibert, H. 1986. Legged Robots that Balance. MIT Press, (1986).

(2) Full. R, et al., Templates and anchors: neuromechanical hypothesesof legged locomotion on land, The Journal of Experimental Biology, Vol.202(1999), pp.3325-3332.

(3) Seyfarth, A et al., A movement criterion for running, The Journal of Biomechanics, Vol.35(2002), pp.649-655.

(4) Talebi, S et al., Quadruped Robot Running With a Bounding Gait, International Symposium on Experimental Robotics, Vol.271(2000), pp.281-289.

(5) Zhang, Z. et al., TowardsRealization of Adaptive Running of a Quadruped Robot Using Delayed Feedback Control, International Conference on Robotics and Automation, Vol.1(2007), pp.4325-4330.

(6) Krasny, P. et al., Generating high-speed dynamic running gaits in aquadruped robot using an evolutionary search, IEEE Transactions on Systems, Man, and Cybernetics, PART B: CYBERNETICS, Vol.34(2004), pp.1685-1696.

(7) Poulakakis, I. et al,, On the Dynamics of Bounding and Extensions Towards the Half-Bound and the Gallop Gaits, International Symposium on Adaptive Motion of Animals and Machines, Vol.1(2003), pp.453-458.

(8) Poulakakis, I. et al., On the Stability of the Passive Dynamics of Quadrupedal Running with a Bounding Gait, The International Journal of Robotics Research, Vol.25(2006), pp.669-687.

(9) Masuda, T. et al., Emergence of a Quadrupedal Bound Gait as Interaction among the Brain, Body and Environment, SICE Annual Conference 2008, Vol.1(2008), pp.2501-2506.

(10) Raibert, H. et al., Animation of Dynamic Legged Locomotion, Proceedings of the 18 th annual conference on Computer graphics and interactive techniques, Vol.25(1991), pp.349-358. 